\title{
DA PÓS-VERDADE A PÓS-IMPRENSA: A CRISE DO JORNALISMO NA ERA DA DESINFORMAÇÃO
}

\section{FROM POST-TRUTH TO POST-PRESS: THE CRISIS OF JOURNALISM IN THE AGE OF DISINFORMATION}

\author{
MARTA THAÍS ALENCAR ${ }^{1}$ \\ JACQUELINE LIMA DOURADO²
}

UNIVERSIDADE FEDERAL DO PIAUÍ

\begin{abstract}
Resumo: Com a popularização das bolhas informativas na internet e a proliferação da desinformação nas redes sociais, o jornalismo vem encontrando desafios e oportunidades diante de uma nova realidade. No contexto atual, grandes empresas de comunicação vêm lidando com contestações, críticas e represálias de políticos e seus seguidores, que tentam deslegitimar o poder e o papel da imprensa no século XXI. Diante disso, o jornalismo vem enfrentando uma crise econômica. É por isso que este artigo tem como objetivo analisar a prática jornalística na Era da Pós-verdade no cenário atual e as iniciativas de fact-checking no Brasil, que atuam na promoção de um jornalismo profissional perante a sociedade e no combate a desinformação e a intolerância.
\end{abstract}

Palavras-chave: Jornalismo; Pós-verdade; Fact-checking.

Abstract: With the popularization of informational bubbles on the Internet and the proliferation of misinformation on social networks, journalism has been facing challenges and opportunities in the face of a new reality. In the current context, major media companies are dealing with challenges, criticism, and reprisals from politicians and their followers who are trying to delegitimize the power and role of the press in the 21 st century. Given this, journalism has been facing an economic crisis. That is why this article aims to analyze the journalistic practice in the Post-Truth Era in the current scenario and the fact-checking initiatives in Brazil, which promote professional journalism in society and fight against misinformation and intolerance.

Keywords: Journalism; Post truth; Fact checking.

\section{INTRODUÇÃO}

A noção de verdade sempre foi motivo de discussão na filosofia, na ciência e no jornalismo. De acordo com Bahia (1990, p.12), a verdade “[...] é um ideal no jornalismo tão

\footnotetext{
${ }^{1}$ Mestranda do Programa de Pós-Graduação em Comunicação da Universidade Federal do Piauí, sob orientação da Prof ${ }^{a} r^{a}$ Jacqueline Lima Dourado. Membra do Grupo de Pesquisas em Comunicação Economia Política e Diversidade (COMUM/UFPI). Bolsista Capes. E-mail: martaalencarpi@outlook.com.

${ }^{2}$ Doutora em Comunicação. Líder do Grupo de Pesquisas em Comunicação Economia Política e Diversidade COMUM/UFPI. Professora do Programa de Pós-Graduação em Comunicação (PPGCOM) da UFPI, e-mail: jacdourado@uol.com.br.
} 
questionado quanto a verdade na justiça." Mas antes de ser verdade jornalística é preciso "[...] saber, afinal, de que verdade falamos quando falamos verdade. [...] Que critério ou critérios nos permitirão estabelecer o que é verdade?” (SOUSA, 2002, p.1).

Foucault (1979, p. 12) argumenta que a "verdade é deste mundo; ela é produzida nele graças às múltiplas coerções e nele produz efeitos regulamentados de poder”. Ainda segundo o autor, cada sociedade tem seu regime de verdade, onde usufrui de mecanismos para diferenciar enunciados verdadeiros dos falsos.

$\mathrm{Na}$ Idade Média, a Igreja impunha que a verdade constava apenas nas Escrituras Sagradas e que tudo acontecia conforme a permissão de Deus. "Para o homem ou mulher pré-modernos, verdade e realidade, combinadas numa só, eram o produto da intenção de Deus, encarnada de uma vez para sempre na forma da Criação de Deus.” (BAUMAN,1998, p.154).

Contrariando os princípios da Igreja na Idade Média, o Iluminismo surgiu na metade do século XVIII, defendendo a razão para o progresso da humanidade. Santos (2017, p.25) afirma que o iluminismo defendia que a racionalidade humana era "[...] a função paradigmática através da qual este enxerga o mundo a sua volta. Todas as verdades até então impostas pelo líder político, ou pelo clero há de passar pelo crivo da razão para ser legitimada”.

Nascimento e Estevam (2016, p. 41) descrevem que a valorização da razão pelo Iluminismo possibilitava o próprio homem “[...] escolher o que deve ou não ser aceito como verdadeiro, através da comprovação científica. Este momento histórico é caracterizado pela exaltação da subjetividade".

A Escola de Frankfurt também conhecida como Institut für Sozialforschung de Frankfut, criada em 1923 na Alemanha (WOLF, 2012), era formada por grandes pensadores, entre eles: Theodor Adorno, Max Horkheimer e Walter Benjamin, que discordavam da razão defendida pelo iluminismo.

De acordo com Nascimento e Estevam (2016), Adorno e Horkheimer interpretaram a ascensão do nazismo, como um exemplo de fracasso da razão e da subjetividade defendidas pelo Iluminismo. "Eles criticam a razão a partir dela própria. Essa crítica à razão é tão incisiva que não sobra nenhuma saída para que o sujeito venha a alcançar sua posterior autonomia, pois a própria tentativa de autonomia já é ela uma forma de aumentar o seu domínio" (NASCIMENTO; ESTEVAM, 2016, p.46).

Quanto à noção de verdade utilizada como instrumento de domínio, Foucault (1979) argumenta que a "verdade está circularmente ligada a sistemas de poder, que produzem e apoiam, e a efeitos de poder que ela induz e que a reproduzem. 'Regime' da verdade." (FOUCAULT, 1979, p.14). Ainda segundo o autor, a economia política da verdade tem cinco características: 
[...] a "verdade" é centrada na forma do discurso científico e nas instituições que o produzem; está submetida a uma constante incitação econômica e política (necessidade de verdade tanto para a produção econômica, quanto para o poder político); é objeto, de várias formas, de uma intensa difusão e de um imenso consumo (circula nos aparelhos de educação ou de informação, cuja extensão do corpo social é relativamente grande, não obstante algumas limitações rigorosas); é produzida e transmitida sob o controle, não exclusivo, mas dominante, de alguns grandes aparelhos políticos e econômicos (universidade, exército, escritura, meios de comunicação) [...] (FOUCAULT, 1979, p.13).

Para Bauman (1998, p.143), a "noção de verdade pertence à retórica do poder". Ainda segundo o autor, a verdade costuma ser utilizada para contestar opiniões diferentes “[...] e quando se torna o objeto da disputa de quem está certo e quem está errado - e quando, por determinadas razões, é importante para alguns ou todos os adversários demonstrar ou insinuar que o outro lado que está errado" (BAUMAN, 1998, p.143).

Intitulada como o "Quarto Poder" desde 1828, a imprensa passou por grandes transformações - de um jornalismo de opinião para um jornalismo de informação, conforme Sousa (2002). Na Modernidade, a imprensa era legitimada como um poder que intermediava entre o Estado e a sociedade, que noticiava informações verídicas e credíveis. Esse conceito assegurava que a credibilidade do jornalista seguia "[...] à risca os procedimentos que consensualmente se identificam com a objectividade" (SOUSA, 2002, p.7).

Devido à ascensão da internet no cenário atual, as relações humanas se configuram cada vez mais em "bolhas" ${ }^{3 "}$ nas redes sociais. Segundo Bauman (2001, p.17), a sociedade está mergulhada em uma modernidade líquida, onde “[...] o tempo moderno se tornou, antes e acima de tudo, a arma na conquista do espaço. [...]”. Neste ambiente virtual, a imprensa vem perdendo influência, poder e credibilidade, que eram marcantes nos séculos XIX e XX.

Ao longo dos tempos, a credibilidade jornalística representou uma espécie de capital simbólico (BOURDIEU,2012) dos veículos. No entanto, a nova sociedade desconsidera esse valor simbólico e acessa novas plataformas de conteúdos, onde processa e coleta informações (KUMAR, 1995). Há profundas mudanças promovidas pela revolução tecnológica que permitem que a sociedade esteja cada vez mais cercada de múltiplas possibilidades de se comunicar e distribuir dados.

Diante dessa avalanche de informações na rede, a credibilidade e a objetividade jornalística estão sendo bastante questionadas por políticos, autoridades e até mesmo pelo público, que é cada vez mais ativo nas redes e não se informa (como em séculos anteriores)

\footnotetext{
3 A expressão "Bolhas virtuais" foi dita pelo autor Eli Pariser descrever o fenômeno na internet. Dentro desse ambiente, os usuários ficam mais propícios a acreditarem em conteúdos que confirmem sua visão de mundo, sem se preocuparem com a veracidade da informação.
} 
somente através de meios tradicionais de comunicação, mas principalmente pela internet e redes sociais. Essa expansão de dados promove ainda outro fenômeno: a proliferação de histórias manipuladas, inverídicas ou inventadas nessas redes.

Isso também tem sido reconhecido como a Era da Pós-verdade ${ }^{4}$, "que surge nesta sociedade 'em bolhas' que se move em torno das pessoas, das suas histórias, de seus costumes e das suas experiências de vida" (TOURAL; CORONEL e POLLYANA, 2019, p.11). Segundo Gooch (2017, p. 15) os algoritmos das redes sociais geram ecossistemas virtuais, "[...] que refletem opiniões correlacionadas, em muitos casos fazendo com que as pessoas criem a sua própria verdade".

Dada a dimensão planetária da penetração dessas "bolhas informativas" e o problema do uso indevido de dados massivos, a identificação dessas desinformações não decorre na atualidade da diligência de robôs, mas ainda do bom e velho trabalho jornalístico investigativo (VITORINO, 2019). Neste cenário, Vizoso, López-García e Pereira-Fariña (2018, p. 106) informam que tem crescido o número de iniciativas de verificação em todo o mundo para combater à desinformação nas redes e a desconfiança do público quanto à atuação da imprensa.

Tanto que um novo gênero de jornalismo, segundo Graves (2016), tem sido utilizado pelas empresas que investem na apuração mais intensa dos fatos: o fact-checking ${ }^{5}$. No Brasil, empresas jornalísticas com versões digitais ou que trabalham diretamente com jornalismo digital, estão ingressando em iniciativas de fact-checking (checagem de dados). A Folha (versão digital do jornal Folha de S. Paulo) é uma delas.

O presente artigo enfatiza que o termo fake news é um termo complexo no contexto atual, mas reconhece que "é uma terminologia antiga - citada pela primeira vez no Século XIX. Ganhou maior repercussão e destaque, no entanto, nas mídias sociais [...]" (FANTE; SILVA; GRAÇA, 2019, p.74). Enquanto Silva, C (2017, p. 36) explica que o que a diferencia a proliferação de informações inverídicas do passado com as da atualidade é a "velocidade, a simplicidade e o baixo custo para produzir e disseminar falsidades com capacidade de proliferação muito rápida e abrangência geográfica imensa”.

${ }^{4}$ O termo "pós-verdade" foi empregado pela primeira vez em 1992, em um artigo do dramaturgo Steve Tesich na revista "The Nation". Mas em 2016, o departamento da Universidade Oxford responsável pela publicação de dicionários, elegeu "pós-verdade" como a palavra do ano da língua inglesa.

${ }^{5}$ A primeira experiência de fact-checking é atribuída ao jornalista Brooks Jackson, que durante as eleições presidenciais de 1992 fez checagem das declarações dos candidatos. Na época, Jackson trabalhava no canal americano de TV por assinatura $\mathrm{CNN}$ e montou uma equipe para analisar a veracidade das declarações e promessas dos presidenciáveis, além de colocar uma etiqueta de "falso" para cada dado equivocado. Em 2003, Jackson ingressou no Centro de Políticas Públicas da Universidade da Pennsylvania e fundou o projeto FactCheck.org. 
Tratando-se de uma pesquisa de natureza exploratória, o corpus é construído com base na observação de matérias da Folha (versão digital do jornal Folha de S. Paulo), divulgadas no período de 18 de outubro a 18 de novembro de 2018. O primeiro passo da pesquisa foi um estudo bibliográfico de artigos acadêmicos, teses e dissertações, livros e reportagens relacionadas à checagem de fatos e Pós-verdade para contextualizar a pesquisa diante do fenômeno atual.

Acrescenta-se ainda a análise e interpretação dos dados com uma abordagem quantiqualitativa, analítico-descritiva, a partir dos métodos da análise de conteúdo (Bardin, 1977). Para tanto, a pesquisa organiza-se em torno de três etapas: Pré-análise; Exploração do material; O tratamento dos resultados, a inferência e a interpretação.

\section{A MORTE DA VERDADE: SEM MENTIRAS, SEM FAKE NEWS, SEM JORNALISMO?}

Como um ex-militar de baixo escalão com discursos contra minorias, políticos de esquerda, pacifistas, feministas, gays e a mídia conseguiu se tornar presidente da Alemanha em 1932? De acordo com Stuenkel (2018, online), os alemães que apoiaram a eleição de Hitler “[...] tinham perdido a fé no sistema político da época. A jovem democracia não trouxera os benefícios que muitos esperavam. [...] Buscava-se um novo rosto. Um anti-político promoveria mudanças de verdade".

Hitler utilizava os meios de comunicação para defender suas ideias e convencer os alemães de seus propósitos. Segundo Stuenkel (2018, online), Hitler “[...] usava um linguajar simples, espalhava fake news, e os jornais adoravam sugerir que muito do que ele dizia era absurdo. Hitler era politicamente incorreto de propósito, o que o tornava mais autêntico aos olhos dos eleitores. Cada discurso era um espetáculo."

Assim como Hitler, o atual presidente dos Estados Unidos, Donald Trump, propagou fake news contra sua adversária, Hilary Clinton, para ganhar a eleição em 2016. Desde o início da campanha em 2016 até o primeiro semestre de 2019, o presidente dos Estados Unidos chegou a declarar mais de 10 mil informações falsas ou enganosas, propagadas em entrevistas, tweets e comícios de campanha (Rizzo, 2019). Nenhum outro político tem um histórico com discursos tão repleto de informações falsas e contraditórias como Trump.

Post-truth (Pós-verdade) inclusive foi considerada a palavra do ano pelo Oxford Dictionaries (Hancock, 2016, online), justamente após eleição presidencial nos Estados Unidos. Feitosa (2017, online) afirma que "[...] o grande garoto-propaganda da pós-verdade continua sendo Donald Trump”. Em seu livro “A Morte da Verdade”, Kakutani (2018, p.7) ressalta que o “ataque à razão 
e à verdade atingiu seu ápice nos Estados Unidos durante o primeiro ano de mandato do presidente Trump [...]".

Diante da expansão da desinformação no mundo, dos ataques e do descrédito à imprensa por parte de Trump e de seus seguidores, Kakutani (2018) afirma que há sinais de alerta com base nas circunstâncias atuais que trazem lembranças da época da Segunda Guerra Mundial. "Quero examinar como descaso pelos fatos, a substituição da razão pela emoção, e a corrosão da linguagem estão diminuindo o valor da verdade, e o que isso significa para os Estados Unidos e para o mundo" (KAKUTANI, 2018, p.3)

Kakutani (2018) destaca que as mentiras de Trump são inúmeras e constantes, desde as investigações sobre a interferência russa nas eleições, a sua popularidade, conquistas etc. Segundo a autora, as mentiras de Trump “[...] são apenas o mais espalhafatoso entre os vários sinais de alerta acerca de seus ataques às instituições democráticas e normas vigentes. Ele ataca rotineiramente a imprensa, o sistema de justiça, as agências de inteligência, o sistema eleitoral [...]" (KAKUTANI, 2018, p.4).

Petrola (2018) afirma que a desqualificação dos grandes veículos de comunicação marcou também a polarização ideológica da campanha eleitoral no Brasil, principalmente devido a Bolsonaro e seus seguidores. Em reportagem de Patrícia Campos Mello, intitulada "Empresas estão comprando pacotes de disparos em massa de mensagens contra o PT no WhatsApp" de 18 de outubro de 2018, a Folha revelou que empresários que apoiaram a campanha do candidato Jair Bolsonaro (PSL) compraram um serviço chamado "disparo em massa", para propagar fake news. Segundo Mello (2018), a Folha apurou que cada contrato chegou a R\$12 milhões.

Após a denúncia da Folha, Bolsonaro pediu aos seus apoiadores, que participassem do período eleitoral de forma democrática e "sem mentiras, sem fake news, sem Folha de S. Paulo" (MARQUES, 2018). Neste cenário, Petrola (2018, p.133) afirma que as informações falsas e os discursos de ódio como os proferidos por Bolsonaro “[...] alcançam tanta repercussão, é porque vão ao encontro de valores e visões de mundo compartilhados por muitos usuários, que as utilizam como forma de identificação com seus grupos num mundo cada vez mais instável e fragmentado".

$\mathrm{Na}$ reportagem "Ataques de Bolsonaro à imprensa chegaram a dez por semana no fim da campanha”, a Folha apresentou dados em que a imprensa foi atacada dez vezes por semana durante o mês de outubro de 2018 pelo candidato Bolsonaro, as evidências das críticas do candidato constavam em mensagens publicadas nas redes sociais, discursos e entrevistas (BALTHAZAR, 2018). 
O levantamento do veículo apresentou 129 ataques de Bolsonaro à imprensa desde o início do ano até o último mês da corrida eleitoral, período em que ocorreram 45 episódios, um terço do total (BALTHAZAR, 2018). "Essa credibilidade vem se mostrando inabalável e atua para dispensar mediações - seja da imprensa, de políticos experientes [...]. Produzir desconfiança em relação à imprensa é inclusive um modo de aumentar a credibilidade da comunicação direta via redes sociais [...]” (ROQUE E BRUNO, 2018, online).

Segundo Petrola (2018, p.116), “[...] a crise de credibilidade do jornalismo tradicional vem se se formando desde a expansão da Internet, com a figura do receptor ativo, o leitor que é também produtor de conteúdos - e que, muitas vezes, exerce também um jornalismo amador nas redes sociais". Enquanto Llorente (2017, p.9) afirma que "o valor ou a credibilidade dos meios de comunicação se veem reduzidos diante das opiniões pessoais".

Artigo das pesquisadoras da Universidade Federal do Rio de Janeiro (UFRJ), Tatiana Roque e Fernanda Bruno, intitulado "Fenômeno da pós-verdade transforma os consensos já estabelecidos" divulgado na Folha no dia 18 de novembro de 2018, revela que mesmo eleito, Jair Bolsonaro continuou a usar as redes sociais para dialogar diretamente com seus seguidores.

Bolsonaro contou com um exército de militantes nas redes que repassavam mensagens para seus grupos de afinidade, divulgando informações que eram enganosas, mas que acreditavam serem verídicas. Além disso, um estudo da organização Avaaz, publicada pela Folha de S. Paulo, apontou que 98,21\% dos eleitores de Jair Bolsonaro (PSL) leram notícias falsas durante a eleição, enquanto 89,77\% acreditaram que as informações enganosas eram verdade (PASQUINI, 2018).

Diante dos ataques do governo Bolsonaro em deslegitimar o papel da imprensa, a Folha lançou em março de 2019 um novo Projeto Editorial, intitulado "Jornalismo profissional é antídoto para notícia falsa e intolerância” (FOLHA, 2019). Em um dos trechos do extenso documento, o veículo destaca seu posicionamento como um jornalismo credível: "Em momentos como este, torna-se ainda mais importante a vigilância independente sobre governos e empresas privadas, reafirmando-se a imagem clássica da imprensa livre como cão de guarda da sociedade e um dos esteios da democracia" (FOLHA, 2019, online).

Quando sofrem represálias de políticos ou do público, os jornalistas utilizam códigos deontológicos e princípios editoriais para se defenderem. Para Cornu (2015, p.106), as empresas jornalísticas “[...] impõem-se a si próprios códigos de conduta sempre que receiam pela sua credibilidade, possuídos pelo sentimento de que muitas derrapagens poderiam incitar o público a descrer deles."

No cenário atual marcado por desconfiança, perda de credibilidade na mídia e proliferação de desinformação na internet, a imprensa tenta se posicionar com o objetivo de 
posicionar no mercado como instrumento de poder confiável e verídico para o público, além de combater a desinformação e os discursos políticos contra o jornalismo.

\section{FACT-CHECKING NA ERA PÓS-VERDADE: A DEFESA DE UM JORNALISMO CRÍVEL}

A política, as autoridades, as empresas e a sociedade perderam um mecanismo de defesa diante da pós-verdade: a intermediação jornalística. Neste contexto, “[...] nunca se fala tanto de comunicação com em uma sociedade que não sabe mais se comunicar consigo mesma, cuja coesão é contestada, cujos valores se desagregam [...]" (SFEZ, 2007, p.12-13). Ainda segundo a autora, o contexto é de uma verdadeira Torre de Babel, onde fala-se cada vez mais, compreende o outro cada vez menos.

Para Zarzalejos (2017), a única maneira de conceber o jornalismo nesta realidade é através da verificação dos dados para detectar as informações inverídicas. Assim, o jornalismo "[...] e a comunicação deontológica, por outro, devem voltar a resgatar o relato verossímil, conter o sentimentalismo, apaziguar e moldar os piores instintos e proclamar a superioridade da inteligência sobre a visceralidade. Este é o fact-checking" (ZARZALEJOS, 2017, p.13).

Inspirados em exemplos norte-americanos, as iniciativas dedicadas a checar as informações proferidas por atores políticos se espalham cada vez mais rápido no mundo, seja em campanha eleitoral ou mesmo em instituições democráticas. Segundo Dourado (2016, online), as iniciativas de fact-checking confrontam a "[...] exatidão dos dados fornecidos por membros da elite do poder público e já repercutidos na mídia, bem como a seguir a trilha das promessas proferidas durante as eleições, numa tentativa de conferir transparência informativa e valorizar a verdade dos fatos".

Silva, N. (2017) salienta que os projetos de fact-checking tem sido um diferencial no mercado diante do jornalismo amador promovido pelo público na internet. "A luta pela sobrevivência na era da informação demonstra como os jornais estão aproveitando esse momento para reforçar suas qualidades de critério e credibilidade, apoiando-se muitas vezes na publicidade e na popularização de funcionais ferramentas de checagem” (SILVA, N., 2017, p.13).

No Brasil, grandes veículos de comunicação no país estão participando de iniciativas de verificação de dados. A Folha é um dos grandes veículos que tem participado desses projetos, um deles é o Comprova, que reuniu jornalistas de 24 diferentes veículos de comunicação para realizar checagem de informações nas eleições de 2018. Além disso, a Folha lançou um blog de factchecking, Folha Informações. Mas antes de lançar o blog, a Folha decidiu não publicar mais 
conteúdo no Facebook, devido à redução de páginas jornalísticas para usuários, com base nos algoritmos.

Além disso, essas iniciativas, como as da Folha, contam também com a participação ativa do público que envia informações suspeitas para as empresas jornalísticas averiguarem. Assim é configurada a substituição das práticas de gatekeeper ${ }^{6}$ por gatewatching ${ }^{7}$ nas redações jornalísticas. "Estas atividades de gatewatching não são nada novas - os próprios jornalistas utilizam práticas semelhantes quando escolhem as matérias [...] envolvendo uma multidão de usuários com interesses diversos [...]” (BRUNS, 2014, p.230-231).

Para Bahia (1990), a apuração permanece como elemento essencial no processo da informação das redações jornalísticas. $\mathrm{Na}$ internet, essa apuração passou por grandes avanços e alterou as rotinas da produção da notícia. "A informação em circulação no ciberespaço permite, potencialmente, avanços no processo de apuração da notícia” (VIRISSIMO, 2009, p.65).

De acordo com Virissimo (2009, p. 84), manter a credibilidade é um desafio constante para os jornalistas que trabalham com verificação dos fatos "[...] e de avaliação das fontes de informação, cuja exatidão se encontra intimamente ligada aos métodos e processos de apuração da notícia. Nesse contexto, faz-se necessário acrescentar outro valor importante para o jornalismo: a associação com a verdade."

Neste contexto, Graves (2013, p.15, tradução nossa), argumenta que os verificadores de fatos "[...] tentam fazer o que mais incomoda o jornalismo convencional: avaliar e, muitas vezes, contradizer as contas oficiais". Além de destacar que os verificadores de fatos continuamente "[...] confrontam a questão do que constitui a verdade objetiva com mais frequência e mais diretamente do que a maioria de seus colegas profissionais" (GRAVES, 2013, p.15).

Com o intuito de exercer uma checagem aprofundada dos fatos com uma abordagem mais objetiva, os fact-checkers chegam a apurar a veracidade de notícias jornalísticas provocando discórdia e confronto com outros jornalistas. Graves (2013, p.236) defende que o jornalismo praticado por verificadores de fatos produz efeitos no mundo, apesar de provocarem reações "[...] que constantemente ameaçam sua reivindicação de objetividade - e sua capacidade de manter sendo relevante da mesma maneira. Esse conflito aparece nos relacionamentos dos verificadores de fatos com leitores, com outros jornalistas e com figuras públicas."

\footnotetext{
${ }^{6} \mathrm{O}$ conceito de gatekeeper foi criado pelo psicólogo Kurt Lewin e aplicado ao jornalismo em 1950 por David Manning White.

${ }^{7}$ O gatekeeping é o processo de seleção das notícias que pode ser comparado a um funil nas redações jornalísticas, no qual muitos dados são colocados e apenas um número restrito consegue chegar ao público. Enquanto o termo gatewatching foi criado em 2005 pelo pesquisador australiano Axel Bruns para descrever um novo modelo de seleção de notícias, onde as audiências têm papel ativo na escolha e construção das notícias.
} 
A partir da análise de matérias da Folha e dos princípios editoriais do veículo, é perceptível que a empresa jornalística está se posicionando para sobreviver no mercado hiperconcorrido existente na internet. Neste ambiente digital, a Folha defende a sua prática jornalística e o seu compromisso com a veracidade dos fatos.

\section{CONSIDERAÇÕES CONCLUSIVAS}

O cenário atual é repleto de desafios para o jornalismo, especialmente diante da polarização política e das bolhas informativas nas redes sociais. Uma pesquisa neste primeiro semestre de 2019 do Instituto Reuters, revelou que os brasileiros confiam 48\% nas notícias em geral diante dos 31\% que acreditam em informações divulgadas nas redes sociais, conforme Carro (2018).

O problema da desinformação no mundo não pode ser resolvido de um dia para o outro, mas o primeiro passo é entender a sua complexidade e apontar soluções que possam contribuir para melhorar às práticas jornalísticas, principalmente quanto à sua objetividade e a busca pela veracidade dos fatos, conforme os códigos deontológicos.

O jornalismo por vários séculos se posicionou como um poder que intermediava entre os políticos e a sociedade, e que buscava incansavelmente pela verdade. No entanto, com os avanços tecnológicos, este quarto poder passou a ser questionado, criticado e descreditado por políticos e seus seguidores. A Folha de S. Paulo, um dos maiores veículos de comunicação do país, lida com diversas críticas do atual presidente e seus seguidores, mas continua a exercer seu trabalho jornalístico com base nos seus princípios editoriais.

Assim, a transparência no método de apuração das informações é um dos valores que está sendo cada vez mais valorizado na Era da Desinformação e também utilizada como reposicionamento das mídias tradicionais no mercado. Para Cornu (2015, p.115), “[...] jornalistas são responsáveis [...] por assegurar uma informação com respeito pelos factos e pelas pessoas. Essa responsabilidade [...] cobre o conjunto dos deveres que se acordam impor ao jornalista nas diversas formulações da sua deontologia profissional".

Pois, o princípio da transparência é relevante tanto para o jornalismo tradicional quanto para iniciativas de fact-checking. Além disso, a contribuição do público na apuração corrobora para que a sociedade possa confiar mais no trabalho jornalístico ao invés de informações divulgadas e compartilhadas nas redes sociais.

Apesar da saturação informativa no mundo, Virissimo (2009, p. 113) argumenta que a apuração jornalística continuará sendo relevante, pois ela promoverá a “[...] efetivação da função 
social que o Jornalismo se propõe cotidianamente em jornais impressos, revistas, programas de rádio, telejornais e portais ou páginas jornalísticas na internet”.

Com base nos desdobramentos deste artigo, as pesquisadoras reconhecem que a noção da verdade é uma questão complexa para a política, a ciência, a filosofia e o jornalismo. Ainda que muitos estudiosos teçam conceitos sobre a palavra verdade haverá sempre divergências e visões contrárias.

É lógico que houve erros e falhas cometidos por jornalistas e empresas de comunicação durante a história. É por isso que as iniciativas de fact-checking neste contexto são tão importantes, porque visam qualificar e aperfeiçoar cada vez mais o trabalho jornalístico. E assim restaurar a confiança do público na imprensa.

\section{REFERÊNCIAS}

BAHIA, Juarez. Jornal, história e técnica: as técnicas do jornalismo. São Paulo: Ática, 1990, p.9-44.

BALTHAZAR, Ricardo. Ataques de Bolsonaro à imprensa chegaram a dez por semana no fim da campanha. Disponível em: https://www1.folha.uol.com.br/poder/2018/11/ataques-debolsonaro-a-imprensa-chegaram-a-dez-por-semana-no-fim-da-campanha.shtml. Acesso em: 13 de jun. 2019.

BARDIN, Laurence. Análise de Conteúdo. Lisboa: Edições 70, 1977.

BAUMAN, Zygmunt. Modernidade líquida. Tradução de Plínio Dentzien. Rio de Janeiro: Zahar, 2001.

O mal-estar da pós-modernidade. Tradução de Mauro Gama e Cláudia Martinelli

Gama. Rio de Janeiro: Jorge Zahar Ed., 1998.

BRUNS, Axel. Gatekeeping, gatewatching, realimentação em tempo real: novos desafios para o jornalismo, Brazilian Journalism Research, v. 10, n. 2, 2014, p.224-247. Disponível em: https://bjr.sbpjor.org.br/bjr/article/view/750. Acesso em: 17 de mar. 2019.

CARRO, Rodrigo. Urban Brazil. Disponível em: http://www.digitalnewsreport.org/survey/2019/brazil-2019/. Acesso em: 19 de jun. 2019.

CORNU, Daniel. Da deontologia do jornalismo à ética da informação. In: PEIXINHO, Ana Teresa. et al. 20 de anos de Jornalismo contra a Indiferença. Coimbra: Imprensa da Universidade de Coimbra, 2015, p. 101-117. Disponível em: http://id.bnportugal.gov.pt/bib/bibnacional/1936019. Acesso em: 16 de jun. 2019. 
DOURADO, Tatiana. Fact-checking como possibilidade de accountability do jornalismo sobre o discurso político: as três iniciativas brasileiras. $40^{\circ}$ Encontro Anual da Anpocs. ST17 Mídias, política e eleições. 2016, Minas Gerais. Anais [...]. Minas Gerais: Anfiteatro Glória, 2016. Disponível em: http://www.anpocs.com/index.php/encontros/papers/40-encontro-anual-daanpocs/st-10/st17-8/10319-fact-checking-como-possibilidade-de-accountability-do-jornalismosobre-o-discurso-politico-as-tres-iniciativas-brasileiras/file. Acesso em: 4 de abr. de 2019.

FANTE, Alexandra; SILVA, Thiago M.; GRAÇA, Valdete. Fake news e Bakthin: gênero discursivo e a (des)apropriação da notícia. In:TOURAL, Carlos; CORONEL, Gabriela; FERRARI, Pollyana (Org). Big Data e Fake News na sociedade do (des)conhecimento. 1. Ed. Aveiro: Ria Editorial, 2019, p.6883. http://www.riaeditorial.com/index.php/big-data-e-fakenews-na-sociedade-do-desconhecimento/. Acesso em: 20 de jun. 2019.

FERRARI, Pollyana. A destruição da esfera pública por meio das fake news. In: TOURAL, Carlos; CORONEL, Gabriela; FERRARI, Pollyana (Org). Big Data e Fake News na sociedade do (des)conhecimento. 1. Ed. Aveiro: Ria Editorial, 2019, p.9-13. http://www.riaeditorial.com/index.php/big-data-e-fake-news-na-sociedade-dodesconhecimento/. Acesso em: 20 de jun. 2019.

FOLHA. Folha Informações. Disponível em: https://www1.folha.uol.com.br/especial/2018/folha-informacoes/\#10. Acesso em: 9 de jun. 2019.

Folha deixa de publicar conteúdo no Facebook. Disponível em: https://www1.folha.uol.com.br/poder/2018/02/ folha-deixa-de-publicar-conteudo-nofacebook.shtml. Acesso em: 21 de jun. 2019.

Jornalismo profissional é antídoto para notícia falsa e intolerância. Disponível em: https://temas.folha.uol.com.br/folha-projeto-editorial/projeto-editorial-folha-de-spaulo/sua-excelencia-o-consumidor-de-noticias.shtml. Acesso em: 23 de jun. 2019.

FOUCAULT, Michel. Microfísica do poder. Tradução e organização de Roberto Machado. 18 ed. Rio de Janeiro: Graal, 1979.

GOOCH, Anthony. No Pós da verdade. Revista Uno, Rio de Janeiro, n.27, 2017, p.14-15. Disponível em: https://www.revista-uno.com.br/wpcontent/uploads/2017/03/UNO_27_BR_baja.pdf. Acesso em: 10 de jun. 2019.

GRAVES, Lucas. Deciding What's True: The Rise of Political Fact-Checking in American Journalism. PhD of Philosophy of the Graduate School of Arts and Sciences. Columbia University Press, New York, 2013. Disponível em: https://academiccommons.columbia.edu/doi/10.7916/D8XG9Z7C.

Acesso em: 7 de mar. 2019.

HANCOCK, Jaime R. Dicionário Oxford dedica sua palavra do ano, 'pós-verdade', a Trump Brexit. D Disponível em: https://brasil.elpais.com/brasil/2016/11/16/internacional/1479308638_931299.html. Acesso em: 7 de jul. 2019.

KAKUTANI, Michiko. A morte da verdade: notas sobre a mentira na Era Trump. Tradução de André Czarnobai e Marcela Duarte. Rio de Janeiro: Intrínseca, 2018. E-book (272 p.).

Cadernos Cajuína, V. 5, N. 1, 2020, p. 88-101. 
KUMAR, Krishan. Da sociedade pós-industrial à pós-moderna. Tradução de Carlos Alberto Medeiros. Rio de janeiro: J. Zahar, 1997.

LLORENTE, José Antonio. A Era da Pós-Verdade: realidade versus percepção. Revista Uno, Rio de Janeiro, n.27, 2017, p.9. Disponível em: https://www.revista-uno.com.br/wpcontent/uploads/2017/03/UNO_27_BR_baja.pdf. Acesso em: 10 de jun. 2019.

MARQUES, José. Folha é a maior fake news do Brasil, diz Bolsonaro a manifestantes. Disponível em: https://www1.folha.uol.com.br/poder/2018/10/folha-e-a-maior-fake-news-dobrasil-diz-bolsonaro-a-manifestantes.shtml. Acesso em: 12 de abr. 2019.

MELLO, Patrícia C. Empresários bancam campanha contra o PT pelo WhatsApp. Disponível em: https://www1.folha.uol.com.br/poder/2018/10/empresarios-bancamcampanha-contra-o-pt-pelo-whatsapp.shtml. Acesso em: 28 de abr. 2019.

NASCIMENTO, Valter; ESTEVAM, Hugo. A crítica à razão no pensamento de Theodor Adorno e Horkheimer. Cadernos Zygmunt Bauman, São Luís, vol. 6, num. 11, 2016. Disponível em: http://www.periodicoseletronicos.ufma.br/index.php/bauman/article/view/5098. Acesso em: 27 de jun. 2019.

PASQUINI, Patrícia. 90\% dos eleitores de Bolsonaro acreditaram em fake news, diz estudo. Disponível em: https://www1.folha.uol.com.br/poder/2018/11/90-dos-eleitores-debolsonaro-acreditaram-em-fake-news-diz-estudo.shtml. Acesso em: 23 de jun. 2019.

SANTOS, Victor Siqueira. O ser humano e Deus: O giro antropológico moderno em "O ser e Deus" de Paul Tillich. 2017. Dissertação (Mestrado em Teologia). Pontifícia Universidade Católica do Rio de Janeiro (PUC-Rio), 212 f., 2017. Disponível em: https://www.maxwell.vrac.puc-rio.br/33800/33800.PDF. Acesso em: 10 de jul. 2019.

SFEZ, Lucien. A comunicação. Tradução de Marcos Marcionilo. São Paulo: Martins, 2007.

SILVA, Carlos. Morte e vida da imprensa. Revista de Jornalismo ESPM, São Paulo, ano 6, n.19, jan-jun. 2017, p. 36-38. Disponível em: http://arquivo.espm.br/revista/jornalismo/2017jan-jun/38-39/\#zoom=z. Acesso em: 4 de jun.2019.

SILVA, Nayane M. R. Fake News: a revitalização do jornal e os efeitos Fact-Checking e CrossCheck no noticiário digital. Temática, Paraíba, ano XIII, n. 08, agos. 2017, p. 12-29. Disponível em: http://periodicos.ufpb.br/index.php/tematica/article/view/35728. Acesso em: 10 de abr. de 2019.

SOUSA, Américo. A retórica da verdade jornalística. Biblioteca online de ciências da comunicação, Portugal, 2002. Disponível em: http://www.bocc.ubi.pt/pag/sousa-americoretorica-verdade-jornalistica.pdf. Acesso em: 28 de maio. 2019.

STUENKEL, Oliver. Por que votamos em Hitler. Disponivel em: https://brasil.elpais.com/brasil/2018/10/06/opinion/1538852257_174248.html. Acesso em: 8 de jul. 2019. 
RIZZO, Salvador. Fact-checking President Trump's reelection campaign kickoff. https://www.washingtonpost.com/politics/2019/06/19/fact-checking-president-trumpsreelection-campaign-kickoff/. Acesso em: 24 de jun. 2019.

ROQUE, Tatiana; BRUNO, Fernanda. Fenômeno da pós-verdade transforma os consensos já estabelecidos.

Disponível

em:

https://www1.folha.uol.com.br/ilustrissima/2018/11/fenomeno-da-pos-verdade-transforma-osconsensos-ja-estabelecidos.shtml. Acesso em: 2 de jul. 2019.

TUCHMAN, Gaye. A objectividade como ritual estratégico: uma análise das noções de objectividade dos jornalistas. In: TRAQUINA, Nelson (org.). Questões, teorias e “estórias". Veja, 2.ed., 1999, p. 74-90.

VIRISSIMO, Vivian. Apuração na Internet: Definição e Características. Um Estudo de caso com jornalistas de rádio, televisão, jornal e internet do Grupo RBS em Florianópolis. 2009. 160f. Dissertação (Mestrado em Jornalismo), Universidade Federal de Santa Catarina, Florianópolis, 2009. Disponível em: http://repositorio.ufsc.br/xmlui/handle/123456789/93028. Acesso em: 9 de mar. 2019.

WOLF, Mauro. Teorias da comunicação. 6. ed. São Paulo: WMF/Martins Fontes, 2012.

VIZOSO, Angel; LÓPEZ-GARCÍA, Xosé; Pereira-Fariña, Xosé. Habilidades tecnológicas como factor clave en el perfil del fact checker para la verificación de la información en la sociedad red. Communication Studies, Portugal, n ${ }^{\circ}$ 27, vol.1, p. 105-126, dez. 2018. Disponível em: http://ojs.labcom-ifp.ubi.pt/index.php/ec/article/view/356. Acesso em: 14 de maio. 2019.

ZARZALEJOS, José Antonio. Comunicação, jornalismo e fact-checking. Revista Uno, Rio de Janeiro, n.27, 2017, p.11-13. Disponível em: https://www.revista-uno.com.br/wpcontent/uploads/2017/03/UNO_27_BR_baja.pdf. Acesso em: 10 de jun. 2019. 